\title{
Hypofractionated Proton Beam Therapy for cT1-2N0M0 Non-small Cell Lung Cancer Patients With Interstitial Lung Disease
}

\author{
TAKASHI SAITO ${ }^{1}$, KAYOKO OHNISHI $^{1,2}$, HITOSHI ISHIKAWA ${ }^{1,3}$, MASATOSHI NAKAMURA $^{4}$, \\ SODAI HOSHIAI ${ }^{5}$, HARUKO NUMAJIRI ${ }^{1}$, KEIKO NEMOTO MUROFUSHI $^{6}$, \\ MASASHI MIZUMOTO ${ }^{1}$, TOSHIYUKI OKUMURA ${ }^{1}$ and HIDEYUKI SAKURAI ${ }^{1}$ \\ ${ }^{1}$ Department of Radiation Oncology, Faculty of Medicine, University of Tsukuba, Tsukuba, Japan; \\ ${ }^{2}$ Department of Radiology, School of Medicine, International University of Health and Welfare, Chiba, Japan; \\ ${ }^{3}$ QST Hospital, National Institutes for Quantum and Radiological Science and Technology, Chiba, Japan; \\ ${ }^{4}$ Department of Radiation Oncology, Japanese Red Cross Medical Center, Tokyo, Japan; \\ ${ }^{5}$ Department of Radiology, Faculty of Medicine, University of Tsukuba, Tsukuba, Japan; \\ ${ }^{6}$ Division of Radiation Oncology, Department of Radiology, \\ Tokyo Metropolitan Cancer and Infectious Diseases Center Komagome Hospital, Tokyo, Japan
}

\begin{abstract}
Background/Aim: To evaluate the outcomes of proton beam therapy (PBT) for early-stage non-small cell lung cancer (NSCLC) in patients with interstitial lung disease (ILD). Patients and Methods: Between 2002 and 2017, 110 patients receiving hypofractionated PBT for CT1-2NOMO NSCLC were reviewed. Results: Of the 110 patients, 17 were diagnosed with ILD. The median follow-up period was 37.8 months. No significant difference in the 1-year cumulative rate of grade $\geq 2$ pneumonitis was observed between patients with and those without ILD (17.6\% vs. $14.1 \%, p=0.708$ ). The lung doses were significantly lower in patients with than in those without ILD among patients without grade $\geq 2$ pneumonitis. There were no significant differences in overall survival or local recurrence-free rates according to the presence of ILD. Conclusion: PBT appears to be a feasible and effective treatment for cT1-2NOMO NSCLC in patients with ILD, but the lung dose should be strictly reduced.
\end{abstract}

Stereotactic body radiation therapy (SBRT) is a standard treatment for medically inoperable patients with stage I nonsmall cell lung cancer (NSCLC) as well as patients who

This article is freely accessible online.

Correspondence to: Kayoko Ohnishi, MD, Ph.D., Department of Radiation Oncology, Faculty of Medicine, University of Tsukuba, 11-1 Tennodai, Tsukuba, Ibaraki, 305-8575, Japan. Tel: +81 298537100, Fax: +81 298537102, e-mail: ohnishi@pmrc.tsukuba.ac.jp

Key Words: Proton beam therapy, interstitial lung disease, non-small cell lung cancer. refuse to undergo surgery. The 3-year rates of local control and overall survival after SBRT range from $73 \%$ to $97 \%$ and from $59 \%$ to $83 \%$, respectively (1-3). The incidence of grade $\geq 2$ radiation pneumonitis, an important toxicity associated with thoracic radiotherapy (RT), was $5-10 \%$ following SBRT among patients with stage I NSCLC (4). However, the risk of developing pneumonitis is particularly high in patients with interstitial lung disease (ILD), and the incidences of grade $\geq 2$ and $\geq 3$ pneumonitis after SBRT were $18-55 \%$ and $10-38 \%$, respectively, in patients with interstitial changes on CT images or with ILD (5-8). Therefore, ILD is considered a relative contraindication for SBRT.

The radiation dose and irradiated volume of the lung are associated with the development of severe pneumonitis after SBRT more frequently in patients with ILD than in those without. Although few studies have analyzed the correlations between dosimetric parameters of the lung and the development of pneumonitis after SBRT in patients with ILD, those that have reported that the lung volume receiving doses of $\geq 5$ Gy (V5), $\geq 10$ Gy (V10), or $\geq 20$ Gy (V20) and the mean lung dose (MLD) were predictive of the development of pneumonitis $(7,8)$. In lung cancer treatment, proton beam therapy (PBT) has the advantage of reducing the irradiated volume and dose to surrounding normal tissue compared with SBRT, because appropriate dose distributions can be achieved using limited irradiation fields (9-13). Therefore, PBT might reduce the risk of severe pneumonitis and provide a treatment option for early-stage NSCLC in patients with ILD. Only one study has evaluated the clinical outcome of hypofractionated PBT for lung tumors in patients with idiopathic pulmonary fibrosis (14). Thus, we conducted 
Table I. Patients, tumor, and treatment characteristics.

\begin{tabular}{|c|c|c|c|c|}
\hline Characteristic & All patients & $\operatorname{ILD}(-)$ & $\operatorname{ILD}(+)$ & $p$-Value \\
\hline $\mathrm{n}$ & 110 & 93 & 17 & \\
\hline Age (years), median (range) & $76(52-88)$ & $75(52-88)$ & $79(64-88)$ & 0.056 \\
\hline \multicolumn{5}{|l|}{ Gender } \\
\hline Male & 86 & 70 & 16 & \multirow[t]{2}{*}{0.084} \\
\hline Female & 24 & 23 & 1 & \\
\hline \multicolumn{5}{|l|}{ PS } \\
\hline 0 & 61 & 54 & 7 & \multirow[t]{4}{*}{0.55} \\
\hline 1 & 40 & 32 & 8 & \\
\hline 2 & 8 & 6 & 2 & \\
\hline 3 & 1 & 1 & 0 & \\
\hline \multicolumn{5}{|l|}{ Smoking history } \\
\hline Never & 16 & 14 & 2 & \multirow[t]{3}{*}{0.43} \\
\hline Ever/Current & 71 & 56 & 15 & \\
\hline Unknown & 23 & 23 & 0 & \\
\hline Serum KL-6 (U/ml), median (range) & $277(127-1,711)$ & $253(127-1,711)$ & $391(159-962)$ & 0.013 \\
\hline \multicolumn{5}{|l|}{ Pulmonary fibrosis score } \\
\hline 1 & & & 11 & \\
\hline 2 & & & 3 & \\
\hline 3 & & & 3 & \\
\hline \multicolumn{5}{|l|}{ Operability } \\
\hline Operable & 56 & 49 & 7 & \multirow[t]{2}{*}{0.38} \\
\hline Inoperable & 54 & 44 & 10 & \\
\hline \multicolumn{5}{|l|}{ Histology } \\
\hline $\mathrm{SqCC}$ & 24 & 20 & 4 & \multirow[t]{4}{*}{0.35} \\
\hline Adenocarcinoma & 44 & 40 & 4 & \\
\hline NSCLC, NOS & 6 & 4 & 2 & \\
\hline Unknown & 36 & 29 & 7 & \\
\hline \multicolumn{5}{|l|}{ UICC $7^{\text {th }}$ T-stage } \\
\hline $\mathrm{T} 1 \mathrm{a}$ & 38 & 32 & 6 & \multirow[t]{4}{*}{0.95} \\
\hline $\mathrm{T} 1 \mathrm{~b}$ & 35 & 30 & 5 & \\
\hline $\mathrm{T} 2 \mathrm{a}$ & 33 & 28 & 5 & \\
\hline $\mathrm{T} 2 \mathrm{~b}$ & 4 & 3 & 1 & \\
\hline CTV (ml), median (range) & $18.2(2.1-107.8)$ & $17.9(2.1-107.8)$ & $18.5(5.8-62.5)$ & 0.66 \\
\hline \multicolumn{5}{|l|}{ Tumor location } \\
\hline Upper lobe & 58 & 50 & 8 & \multirow[t]{3}{*}{0.87} \\
\hline Middle lobe & 11 & 9 & 2 & \\
\hline Lower lobe & 41 & 34 & 7 & \\
\hline \multicolumn{5}{|l|}{ Total dose (RBE) } \\
\hline 66 Gy in 10 fractions & 77 & 63 & 14 & \multirow[t]{2}{*}{0.23} \\
\hline $72.6 \mathrm{~Gy}$ in 22 fractions & 33 & 30 & 3 & \\
\hline
\end{tabular}

ILD: Interstitial lung disease; PS: performance status; KL-6: Krebs von den Lungen-6; UICC: Union for International Cancer Control; SqCC: squamous cell carcinoma; NSCLC: non-small cell lung cancer; NOS: not otherwise specified; CTV: clinical target volume; RBE: relative biological effectiveness.

an institutional retrospective study to assess the safety and efficacy of PBT for early-stage NSCLC in patients with ILD.

\section{Patients and Methods}

Patients. The present study was approved by the institutional review board at University of Tsukuba Hospital (approval no. H30-303). Between April 2002 and December 2017, 135 consecutive patients with cT1-2NOM0 NSCLC, according to the $7^{\text {th }}$ version of the Union for International Cancer Control TNM classification (15), were treated with passive-scattering PBT at our institution. Twenty-five patients were excluded for the following reasons: no evaluable pretreatment computed tomography (CT) images of the lung $(n=21)$, less than 6 months of follow-up $(n=3)$, and insufficient data obtained from the dose-volume histogram (DVH) in the treatment planning system $(n=1)$. The remaining 110 patients were included in this analysis.

Evaluation of interstitial lung disease. A board-certified diagnostic radiologist (S.H.) reviewed the pretreatment CT images of the lung and determined the presence or absence of ILD according to the idiopathic pulmonary fibrosis clinical practice guidelines of the American Thoracic Society (16). If a patient had ILD, the pulmonary 
fibrosis score (PFS), as proposed by Kazerooni et al. (17), was used as the maximum score of the lobe in the whole lung.

Proton beam therapy. For treatment planning, CT images were obtained at 2.5 - or $5.0-\mathrm{mm}$ intervals in the treatment position using a respiratory-gated system during the end-expiratory phase. The patient's body was immobilized using a custom-shaped body cast (ESFORM, Engineering System Co., Matsumoto, Japan). Passivescattering PBT plans were made using the VQA version 1.7 or 2.0 (Hitachi, Tokyo, Japan). PBT was delivered during the endexpiratory phase with $155-250 \mathrm{MeV}$ protons generated using a synchrotron accelerator. Prior to each treatment, the patient's position was confirmed by fluoroscopy.

The clinical target volume (CTV) included the primary tumor, and planning target volume (PTV) comprised the CTV plus a 5- to 8 -mm margin in all directions. In general, two to three ports in the optimal direction were used, and an aperture margin of 5-10 mm (an additional 5-mm margin in the caudal direction to compensate for respiratory motion) was set to cover the entire PTV by enlarging the multi-leaf collimator and adjusting the range shifter. For patients with a high risk of developing radiation pneumonitis, those with ILD comorbidity, those with extremely low pulmonary function (e.g., forced expiratory volume in $1 \mathrm{~s} \leq 700 \mathrm{ml}$ ), and those receiving long-term oxygen therapy, the minimum PTV and aperture margins (e.g., $5 \mathrm{~mm}$ ) were used to reduce the irradiated volume of the lung as much as possible. The following two treatment protocols were used depending on the tumor location: $66.0 \mathrm{~Gy}$ [relative biological effectiveness (RBE)] in 10 fractions for peripherally located tumors and 72.6 Gy (RBE) in 22 fractions for centrally located tumors.

Follow-up procedures and statistical analysis. Post-treatment evaluation was performed every 2-3 months during the first year and every 3-6 months thereafter. The follow-up examinations included physical examinations, blood tests, chest X-rays, and CT or positron emission tomography/CT. Local recurrence at the primary tumor site was defined as an increase in tumor size on serial CT scans, significant positive accumulation on positron emission tomography/CT, or histological confirmation. Treatment-related toxicities including pneumonitis were evaluated according to the Common Terminology Criteria for Adverse Events version 4.0.

Overall survival (OS), recurrence-free survival (RFS), and local recurrence-free (LRF) rates and the cumulative rate of pneumonitis were calculated from the first day of PBT to the date of the event or the last follow-up using the Kaplan-Meier method. Differences between survival curves were assessed using the log-rank test. Student's $t$-test was used to compare background clinical factors between two groups. Dosimetric parameters of the lung obtained from DVHs were compared between groups using the MannWhitney $U$-test, and cut-off values of these parameters for predicting the development of grade $\geq 2$ pneumonitis were calculated using receiver operating characteristic analysis. A $p$-value $<0.05$ was considered statistically significant. All statistical analyses were performed using JMP version 13 (SAS institute, Cary, NC, USA).

\section{Results}

Patient and treatment characteristics. The patient, tumor, and treatment characteristics are shown in Table I. The patients comprised 86 men $(78.1 \%)$, and the median age was 76 years (range $=52-88$ years). NSCLC was confirmed

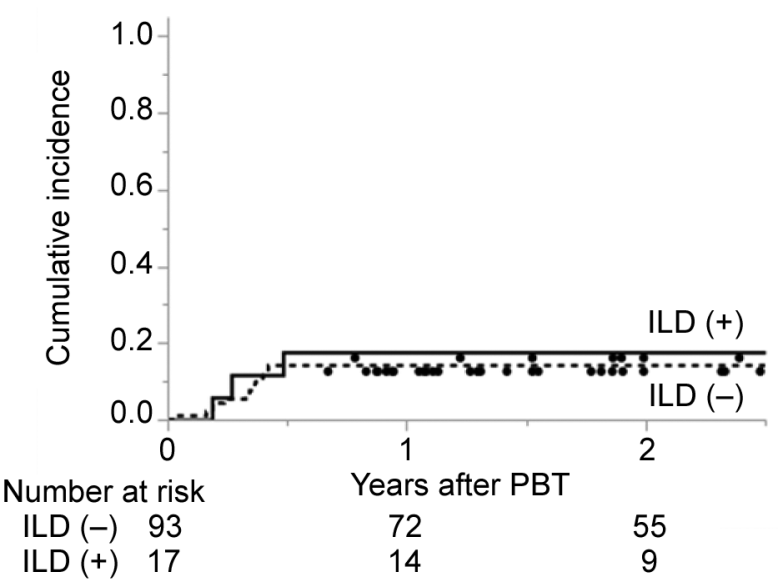

Figure 1. Cumulative rates of grade $\geq 2$ pneumonitis after proton beam therapy $(P B T)$. Straight and dashed lines show the cumulative rates of grade $\geq 2$ pneumonitis in patients with and those without interstitial lung disease (ILD), respectively.

histologically in 74 patients $(67.2 \%)$. The clinical $\mathrm{T}$ stages were T1a $(\mathrm{n}=38 ; 34.6 \%)$, T1b $(\mathrm{n}=35 ; 31.8 \%)$, T2a $(\mathrm{n}=33$; $30.0 \%)$, and T2b $(n=4 ; 3.6 \%)$. Total doses of 66.0 Gy (RBE) in 10 fractions and $72.6 \mathrm{~Gy}$ (RBE) in 22 fractions were prescribed to 77 and 33 tumors, respectively. The median follow-up period was 37.8 months (range=2.1-176.9 months) in all patients and 43.1 months (range=6.3-176.9 months) in the surviving patients.

Of the 110 patients, 17 had ILD on pretreatment CT images. Among them, PFSs of 1, 2, and 3 were observed in 11,3 , and 3 patients, respectively, but no patient had a PFS $\geq 4$. There were no significant differences in the patient, tumor, or treatment factors between the patients with and those without ILD, except for the serum level of Krebs von den Lungen-6, which was lower in the patients without ILD.

Pneumonitis and dose-volume histogram parameters of the lung. Grade 2 and 3 pneumonitis was observed in $10(9.1 \%)$ and $6(5.4 \%)$ patients, respectively, but no grade 4 or 5 pneumonitis was found. The incidences of grade 2 and 3 pneumonitis were $11.7 \%$ and $5.8 \%$ in patients with ILD and $8.6 \%$ and $5.4 \%$ in those without ILD, respectively. The 1 -year cumulative rate of grade $\geq 2$ pneumonitis in all patients was $14.6 \%$ [confidence interval $(C I)=9.1-22.6$ ], and there was no significant difference in this rate between patients with and those without ILD (17.6\% vs. 14.1\%, $p=0.708)$ (Figure 1). Details regarding the pneumonitis cases are shown in Table II. For patients with ILD, grade $\geq 2$ pneumonitis developed in one $(7.1 \%)$ of 14 patients with a PFS of 1 or 2 and in two $(66.6 \%)$ of three patients with a PFS of 3 .

The DVH parameters of the lung according to the presence of ILD and pneumonitis are shown in Table III. Among the 
Table II. Details of the pneumonitis cases according to the presence of interstitial lung disease.

\begin{tabular}{|c|c|c|c|c|c|}
\hline \multirow[t]{2}{*}{ Pneumonitis } & \multirow{2}{*}{$\begin{array}{c}\text { All } \\
(n=110)\end{array}$} & \multirow{2}{*}{$\begin{array}{c}\operatorname{ILD}(-) \\
(\mathrm{n}=93)\end{array}$} & \multicolumn{3}{|c|}{$\operatorname{ILD}(+)$} \\
\hline & & & PFS $1(n=11)$ & PFS $2(n=3)$ & PFS $3(n=3)$ \\
\hline Grade 0,1 & $94(85.5 \%)$ & $80(86.0 \%)$ & $10(90.9 \%)$ & $3(100 \%)$ & $1(33.3 \%)$ \\
\hline Grade 2 & $10(9.1 \%)$ & $8(8.6 \%)$ & $1(9.1 \%)$ & $0(0 \%)$ & $1(33.3 \%)$ \\
\hline Grade 3 & $6(5.4 \%)$ & $5(5.4 \%)$ & $0(0 \%)$ & $0(0 \%)$ & $1(33.3 \%)$ \\
\hline Grade 4,5 & $0(0 \%)$ & $0(0 \%)$ & $0(0 \%)$ & $0(0 \%)$ & $0(0 \%)$ \\
\hline
\end{tabular}

ILD: Interstitial lung disease; PFS: pulmonary fibrosis score.

Table III. Parameters from lung dose-volume histograms according to the presence of interstitial lung disease and pneumonitis.

\begin{tabular}{|c|c|c|c|c|}
\hline DVH parameter & Pneumonitis & $\operatorname{ILD}(-)(\mathrm{n}=93)$ & $\operatorname{ILD}(+)(n=17)$ & $p$-Value \\
\hline \multirow[t]{4}{*}{ V5, median (range) } & All & $11.2 \%(4.5-31.8 \%)$ & $8.0 \%(4.5-20.9 \%)$ & 0.011 \\
\hline & Grade $\leq 1$ & $10.8 \%(4.5-31.8 \%)$ & $7.7 \%(4.5-20.9 \%)$ & 0.016 \\
\hline & Grade $\geq 2$ & $14.5 \%(6.5-31.5 \%)$ & $11.2 \%(7.2-12.3 \%)$ & 0.200 \\
\hline & $p$-Value & 0.064 & 0.377 & \\
\hline \multirow[t]{4}{*}{ V10, median (range) } & All & $10.0 \%(3.9-29.2 \%)$ & $7.1 \%(3.9-18.2 \%)$ & 0.009 \\
\hline & Grade $\leq 1$ & $9.5 \%(3.9-29.0 \%)$ & $6.7 \%(3.9-18.2 \%)$ & 0.017 \\
\hline & Grade $\geq 2$ & $12.3 \%(5.8-29.2 \%)$ & $8.7 \%(6.0-11.3 \%)$ & 0.178 \\
\hline & $p$-Value & 0.066 & 0.412 & \\
\hline \multirow[t]{4}{*}{ V20, median (range) } & All & $8.0 \%(2.7-25.9 \%)$ & $5.9 \%(3.0-13.3 \%)$ & 0.012 \\
\hline & Grade $\leq 1$ & $7.7 \%(2.7-24.6 \%)$ & $5.5 \%(3.0-13.3 \%)$ & 0.021 \\
\hline & Grade $\geq 2$ & $10.0 \%(4.8-25.9 \%)$ & $7.2 \%(4.4-9.7 \%)$ & 0.157 \\
\hline & $p$-Value & 0.055 & 0.412 & \\
\hline \multirow[t]{4}{*}{ MLD, median (range) } & All & 4.0 Gy (1.4-15.9 Gy) & 3.1 Gy (1.5-7.6 Gy) & 0.015 \\
\hline & Grade $\leq 1$ & 3.9 Gy (1.4-13.0 Gy) & 2.9 Gy $(1.5-7.6 \mathrm{~Gy})$ & 0.028 \\
\hline & Grade $\geq 2$ & $5.1 \mathrm{~Gy}(2.5-15.9 \mathrm{~Gy})$ & 4.3 Gy $(2.3-4.3 \mathrm{~Gy})$ & 0.121 \\
\hline & $p$-Value & 0.051 & 0.283 & \\
\hline
\end{tabular}

DVH: Dose-volume histogram; ILD: interstitial lung disease; V5: lung volume receiving a dose of $\geq 5$ Gy; V10: lung volume receiving a dose of $\geq 10 \mathrm{~Gy}$; V20: lung volume receiving a dose of $\geq 20 \mathrm{~Gy}$; MLD: mean lung dose.

patients without ILD, the median lung V5, V10, and V20 and the MLD were higher, with marginal significance, in patients who developed grade $\geq 2$ pneumonitis compared with grade $\leq 1$ pneumonitis $(14.5 \%$ vs. $10.8 \%, p=0.064 ; 12.3 \%$ vs. $9.5 \%$, $p=0.066 ; 10.0 \%$ vs. $7.7 \%, p=0.055$; and 5.1 vs. $3.9 \mathrm{~Gy}$, $p=0.051$ ). On the other hand, a similar tendency was not found among the patients with ILD. In patients with grade $\leq 1$ pneumonitis, the lung V5, V10, and V20 and the MLD were significantly lower in patients with than those without ILD (7.7\% vs. $10.8 \%, p=0.016 ; 6.7 \%$ vs. $9.5 \%, p=0.017 ; 5.5 \%$ vs. $7.7 \%, p=0.021$; and $2.9 v s .3 .9 \mathrm{~Gy}, p=0.028)$, but there were no significant differences according to the presence of ILD in patients with grade $\geq 2$ pneumonitis. Figure 2 shows the cutoff values of the lung V5, V10, and V20 and MLD for predicting the development of grade $\geq 2$ pneumonitis, determined using receiver operating characteristic curves.

Survival and local control. The 3-year rates of OS, RFS, and LRF of all patients were $78.2 \%(95 \% \mathrm{CI}=68.8-85.4), 61.9 \%$
(95\% CI=52.3-70.7), and $88.9 \% \quad(95 \% \quad \mathrm{CI}=80.5-94.0)$, respectively. The corresponding rates of the patients with ILD were $72.3 \%(95 \% \mathrm{CI}=44.8-89.3), 61.6 \%$ (95\%CI=36.4$81.7)$, and $85.5 \%(95 \% \mathrm{CI}=56.7-96.3)$, respectively, and those of the patients without ILD were $79.3 \%(95 \% \mathrm{CI}=68.8-87.4)$, $62.0 \%(95 \% \mathrm{CI}=51.6-71.5)$, and $89.6 \%(95 \% \mathrm{CI}=80.4-94.7)$, respectively (Figure 3 ). No significant differences in OS $(p=0.077)$, RFS $(p=0.502)$, or LRF $(p=0.220)$ rates were observed between patients with and those without ILD.

\section{Discussion}

SBRT for early-stage lung cancer in patients with ILD can cause severe or fatal pneumonitis. There are several studies so far that have evaluated the outcomes of SBRT for lung tumors in patients with ILD, many of which have been conducted in Japan (5-8, 18-20). As shown in Table IV, the incidences of grade $\geq 2, \geq 3$, and 5 pneumonitis after SBRT in patients with ILD were 18.7-55.0\%, 10.0-38.8\%, and 0- 


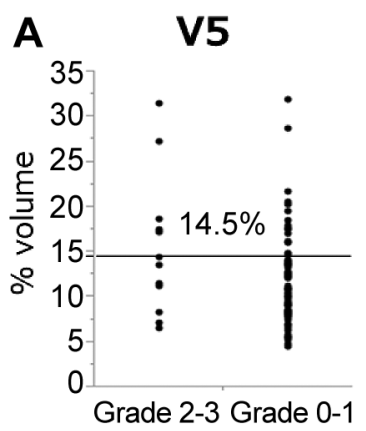

B

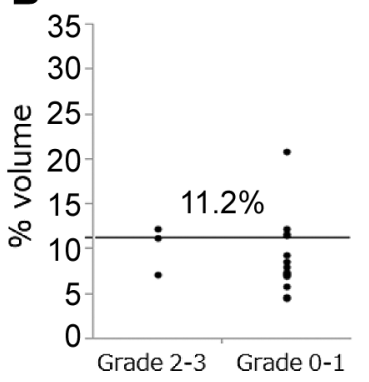

V10
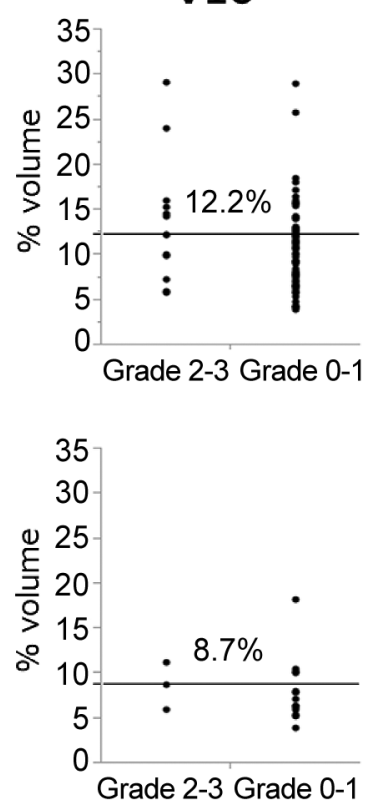

V20
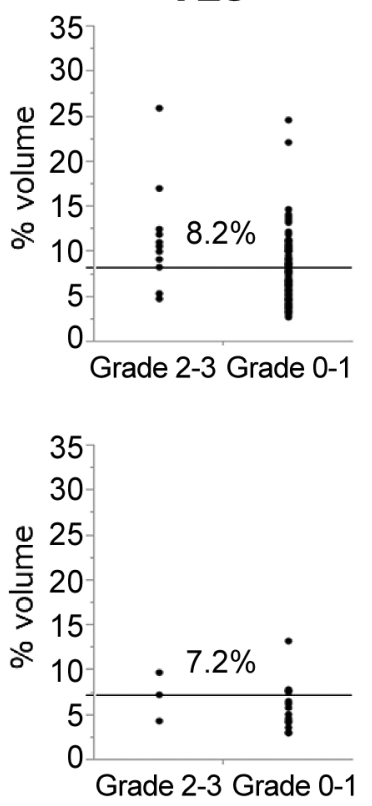

MLD
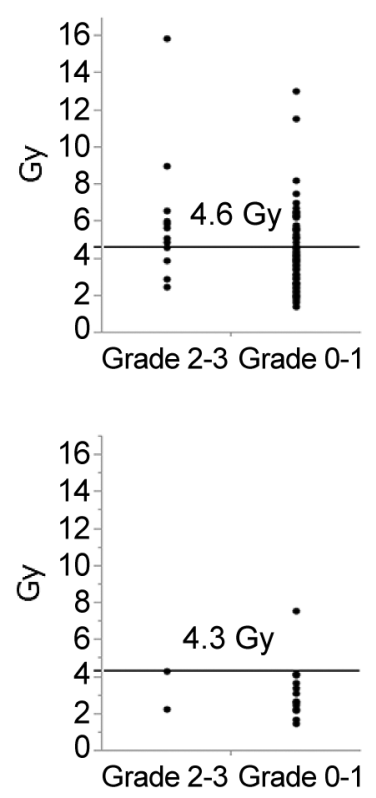

Figure 2. Dosimetric parameters in patients with and those without grade $\geq 2$ pneumonitis. Horizontal bars show the cut-off values calculated using receiver operating characteristic curves. (A) Patients without ILD and (B) patients with ILD.

$21 \%$, respectively $(5-8,18-20)$. Because there is an apparent dose-volume effect of SBRT in the lung on radiationinduced pneumonitis in patients with lung tumors $(7,8,20)$, particle therapy including PBT, which can provide a better dose distribution compared with SBRT, is theoretically safer than photon-based SBRT for providing curative radiation doses in patients with ILD. In our study, the incidence of grade $\geq 2$ pneumonitis in patients with ILD was $17.6 \%$ and was comparable with the rates reported in previous particle therapy studies $(14,21,22)$. Although the particle therapy series included more patients with larger (T2-3) tumors compared with the SBRT series, the incidence of pneumonitis induced by particle therapy appears to be lower than that induced by SBRT $(5-8,18-20)$ (Table IV).

We also aimed to identify predictive factors associated with pneumonitis development after PBT in patients with ILD to establish optimal thoracic RT conditions for patients with ILD. Although several factors associated with ILD have been reported to predict severe pneumonitis development after SBRT for NSCLC, including pretreatment serum levels of Krebs von den Lungen-6 and surfactant protein-D, diffusing capacity of the lungs for carbon monoxide, oxygen dependence, non-target lung FDG uptake, and severity of ILD (23-25), there are no established criteria for offering RT as an acceptable treatment option to patients with ILD. The PFS proposed by Kazerooni is used to evaluate the severity of idiopathic pulmonary fibrosis and is correlated with the pathological changes of fibrosis (17). In the present study, the incidence of grade $\geq 2$ pneumonitis in patients with a PFS of 3 was $66.6 \%$, whereas the corresponding rate was $7.1 \%$ in patients with a PFS of 1 or 2 . Tsujino et al. reported that the PFS combined with the lung V20, absolute lung volume spared from a 5 Gy dose, and age can improve the predictability of developing severe radiation pneumonitis in NSCLC patients treated with chemoradiotherapy, supporting our results (26). The PFS on pretreatment CT images may help select patients with ILD appropriate for PBT for earlystage NSCLC.

Thus, PBT seems to be safe for cT1-2N0M0 NSCLC patients with a PFS of $1 / 2$ even if they have ILD, but it was unclear whether PBT is truly safe for patients with ILD because their PTV margins were carefully reduced. There was no difference in the CTV between patients with and those without ILD, but the lung V5-20 and MLD were significantly lower in the patients with than in those without ILD (Table III). On the other hand, our treatment policy seems to be acceptable because there was no difference in RFS or LRF between the groups. Hence, the dose constraints of the lung as well as the setting of the PTV are very important in terms of the efficacy and toxicity of RT for cT12N0M0 NSCLC patients with ILD.

Only a few studies have reported the DVH parameters associated with the development of pneumonitis after SBRT in patients with ILD. Yoshitake et al. reviewed 260 patients who 


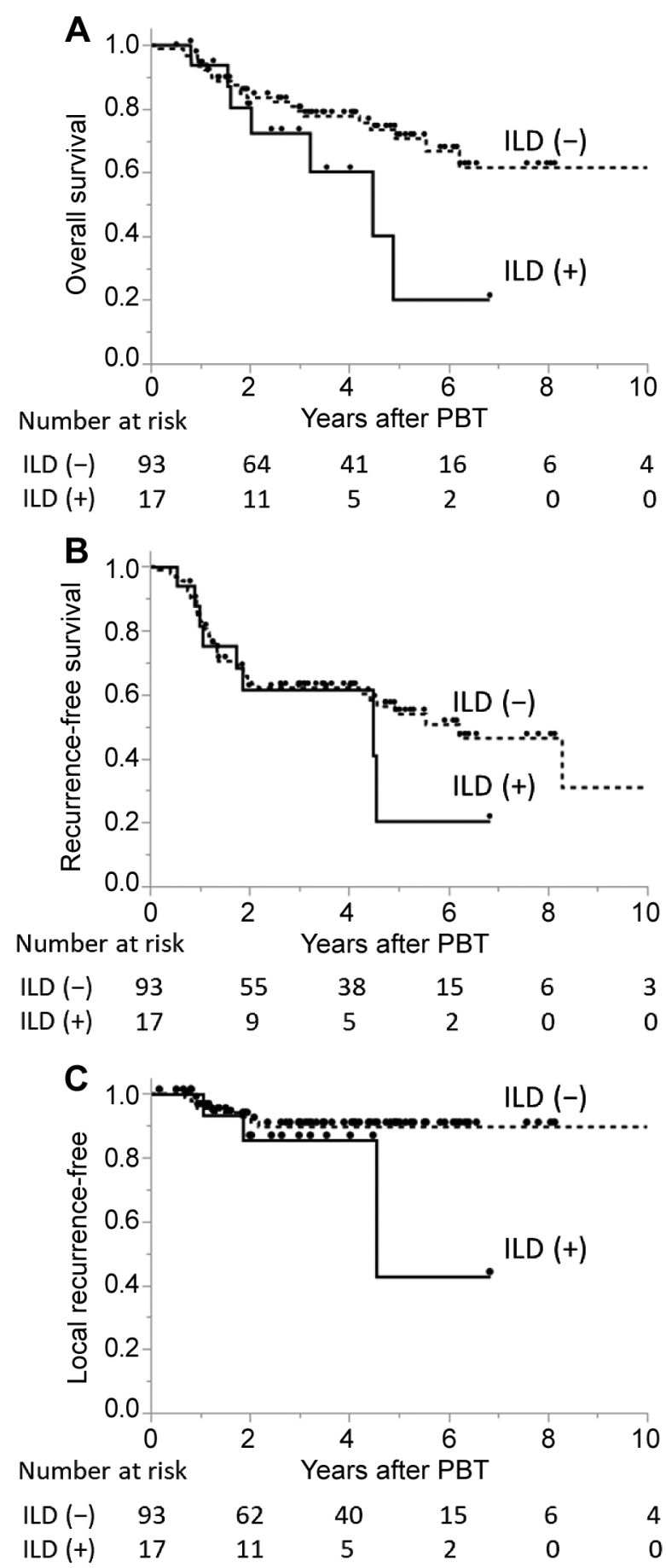

Figure 3. Kaplan-Meier curves of survival and local recurrence-free rates according to the presence (straight lines) or absence (dashed lines) of interstitial lung disease (ILD). (A) Overall survival, (B) recurrence-free survival, and $(C)$ local recurrence-free rates.

received SBRT for lung cancer, including 18 with interstitial changes on pretreatment $\mathrm{CT}$, and reported a significantly higher 6-month cumulative rate of grade $\geq 2$ pneumonitis in the patients with than in those without interstitial changes $(44.4 \%$ vs. $4.1 \%$, $p<0.0001$ ), whereas there was no significant difference in the lung V5, V10, or V20 or the MLD (7). Liu et al. evaluated 109 early-stage NSCLC patients receiving SBRT, including 38 with subclinical ILD, and reported that the MLD was significantly higher in patients with grade $\geq 2$ pneumonitis than in those with grade $\leq 1$ pneumonitis among patients with subclinical ILD (5.5 Gy vs. $3.4 \mathrm{~Gy}, p=0.042$ ) (20). Their findings suggest that stricter dose constraints of the lung are required when treating patients with ILD. In the present study, however, there were no significant differences in DVH parameters between ILD patients with grade $\geq 2$ and those with grade $\leq 1$ pneumonitis, although dose-volume effects on the development of pneumonitis were seen in patients without ILD. Similarly, Ono et al. could not determine any cut-off levels for DVH parameters in NSCLC patients with ILD treated with PBT (14). In our study, the cutoff values of the lung V5 and V10 and the MLD of all three patients who developed grade $\geq 2$ pneumonitis among those with ILD were lower than the respective values among the patients without ILD. One explanation for these results is that our values were very low compared with those obtained after SBRT. Dosimetric risk factors for pneumonitis after SBRT in patients with ILD were reported to be a lung V5 $\geq 18 \%, \mathrm{~V} 10 \geq 12 \%$, and MLD $\geq 4$ Gy (7). The median lung V5 and V10 and MLD of the patients with ILD in the present study were only $8.0 \%$, $7.1 \%$, and $3.1 \mathrm{~Gy}$, respectively. Thus, physiological superiority of PBT over SBRT contributed to a lower incidence of grade $\geq 2$ pneumonitis (17.6\%), with no grade 5 pneumonitis, after PBT in the present study. Conversely, the DVH parameters of the lung with asymptomatic (grade $\leq 1$ ) pneumonitis were significantly lower in patients with than in those without ILD. Therefore, the abovementioned approaches in addition to reducing the lung dose using protons and carbon-ions are necessary to determine patient eligibility for curative RT after further data accumulation.

The major limitations of this study were its retrospective nature and small number of patients from a single institution. However, the number of patients with ILD referred to radiation oncologists is low because it is unclear whether RT, including PBT, is beneficial for NSCLC patients with ILD. Although the limitations of this study were unavoidable, a future large-scale multi-institutional study should be conducted. At present, NSCLC patients treated with RT using protons and carbon-ions in Japan are being prospectively registered, and the resulting data will not only confirm the effectiveness but also determine patient eligibility and the optimal treatment conditions in terms of safety.

In conclusion, passive-scattering PBT seems to be a feasible and effective treatment option for cT1-2N0M0 NSCLC patients with ILD. Patients with a maximum PFS of $1 / 2$ who receive PBT have a low incidence of symptomatic pneumonitis if protons are used. However, predictive markers of pneumonitis after PBT for patients with a PFS of 
Saito et al: Proton Beam Therapy for Early-stage NSCLC in Patients With ILD

Table IV. Summary of the outcomes of SBRT and hypofractionated particle therapy for lung tumors in patients with ILD.

\begin{tabular}{|c|c|c|c|c|c|c|c|c|c|c|}
\hline \multirow[t]{2}{*}{ Author } & \multirow[t]{2}{*}{ Modality } & \multirow{2}{*}{$\begin{array}{l}\text { No. of ILD } \\
\text { patients }\end{array}$} & \multirow{2}{*}{$\begin{array}{c}\text { Median } \\
\text { age }\end{array}$} & \multirow{2}{*}{$\begin{array}{c}\text { Primary/ } \\
\text { Metastatic } \\
\text { tumor cases }\end{array}$} & \multirow[t]{2}{*}{$\mathrm{T} 1 / \mathrm{T} 2 / \mathrm{T} 3$} & \multirow[t]{2}{*}{ OS (year) } & \multicolumn{4}{|c|}{ Pneumonitis } \\
\hline & & & & & & & Grade $\geq 2$ & Grade $\geq 3$ & Grade 5 & Criteria \\
\hline Yamaguchi et al. (5) & SBRT & 16 & N/A & N/A & N/A & $48 \%(3)$ & $18.7 \%$ & $18.7 \%$ & $6.2 \%$ & CTCAE v. 3.0 \\
\hline Ueki et al. (6) & SBRT & 20 & 78 & $20 / 0$ & $14 / 6 / 0$ & $54 \%(3)$ & $55.0 \%$ & $10.0 \%$ & $0 \%$ & CTCAE v.3.0 \\
\hline Yoshitake et al. (7) & SBRT & 18 & 75 & $18 / 0$ & N/A & $49 \%(2)$ & $50.0 \%$ & $38.8 \%$ & $16.7 \%$ & CTCAE v.4.0 \\
\hline Onishi et al. (8) & SBRT & 242 & 77 & $242 / 0$ & $160 / 82 / 0$ & $42 \%(3)$ & N/A & $12.4 \%$ & $6.9 \%$ & N/A \\
\hline Bahig et al. (18) & SBRT & 28 & 76 & $28 / 0$ & N/A & N/A & N/A & $32 \%$ & $21 \%$ & CTCAE v. 3.0 \\
\hline Glick et al. (19) & SBRT & 39 & 78 & $35 / 4$ & N/A & $36 \%(3)$ & $20.5 \%$ & $10.3 \%$ & $5.1 \%$ & CTCAE v. 3.0 \\
\hline Liu et al. (20) & SBRT & 38 & N/A & $38 / 0$ & N/A & $\mathrm{N} / \mathrm{A}$ & $47.3 \%$ & $10.5 \%$ & $2.6 \%$ & CTCAE v.5.0 \\
\hline Nakajima et al. (21) & CIRT & 29 & 73 & $29 / 0$ & $10 / 19 / 0$ & $46 \%(3)$ & $41.0 \%$ & $27.5 \%$ & $0 \%$ & CTCAE v.3.0 \\
\hline Okano et al. (22) & CIRT & 26 & 76 & $26 / 0$ & $18 / 8$ & $59 \%(3)$ & $7.6 \%$ & $3.8 \%$ & $0 \%$ & CTCAE v.4.0 \\
\hline Ono et al. (14) & PBT & 16 & 76 & $15 / 1$ & $7 / 6 / 2$ & $44 \%(2)$ & $18.7 \%$ & $12.5 \%$ & $6.2 \%$ & CTCAE v. 3.0 \\
\hline Current study & PBT & 17 & 79 & $17 / 0$ & $11 / 6 / 0$ & $72 \%(3)$ & $17.6 \%$ & $5.8 \%$ & $0 \%$ & CTCAE v.4.0 \\
\hline
\end{tabular}

SBRT: Stereotactic body radiation therapy; ILD: interstitial lung disease; OS: overall survival; N/A: not available; CTCAE: Common Terminology Criteria for Adverse Events; CIRT: carbon ion radiotherapy; PBT: proton beam therapy.

3 should be confirmed to determine the PBT indications and optimal treatment method in future studies.

\section{Conflicts of Interest}

The Authors have no conflicts of interest to disclose regarding this manuscript.

\section{Authors' Contributions}

Conceptualization, TS and $\mathrm{KO}$; methodology, HI, TS, and KO; investigation, TS, $\mathrm{KO}, \mathrm{SH}$, and $\mathrm{MN}$; resources, $\mathrm{KO}, \mathrm{HN}$, KNM, MM, and TO; data collection, TS and $\mathrm{KO}$; writing (original draft preparation), TS and KO; writing (review and editing), HI; supervision, HS.

\section{Acknowledgements}

The Authors are grateful to JAM Post (www.jamp.com) for their editing services.

\section{References}

1 Nagata Y, Hiraoka M, Shibata T, Onishi H, Kokubo M, Karasawa K, Shioyama Y, Onimaru R, Kozuka T, Kunieda E, Saito T, Nakagawa K, Hareyama M, Takai Y, Hayakawa K, Mitsuhashi N and Ishikura S: Prospective trial of stereotactic body radiation therapy for both operable and inoperable T1N0M0 non-small cell lung cancer: Japan Clinical Oncology group study JCOG0403. Int J Radiat Oncol Biol Phys 93(5): 989-996, 2015. PMID: 26581137. DOI: 10.1016/j.ijrobp.2015.07.2278

2 Shibamoto Y, Hashizume C, Baba F, Ayakawa S, Manabe Y, Nagai A, Miyakawa A, Murai T, Iwata H, Mori Y, Mimura M and Ishikura S: Stereotactic body radiotherapy using a radiobiology-based regimen for stage I nonsmall cell lung cancer: a multicenter study. Cancer 118(8): 2078-2084, 2012. PMID: 22009495. DOI: 10.1002/cncr.26470
3 Nagata Y, Takayama K, Matsuo Y, Norihisa Y, Mizowaki T, Sakamoto T, Sakamoto M, Mitsumori M, Shibuya K, Araki N, Yano S and Hiraoka M: Clinical outcomes of a phase I/II study of $48 \mathrm{~Gy}$ of stereotactic body radiotherapy in 4 fractions for primary lung cancer using a stereotactic body frame. Int J Radiat Oncol Biol Phys 63(5): 1427-1431, 2005. PMID: 16169670. DOI: $10.1016 /$ j.ijrobp.2005.05.034

4 Zhao J, Yorke ED, Li L, Kavanagh BD, Li XA, Das S, Miften M, Rimner A, Campbell J, Xue J, Jackson A, Grimm J, Milano MT and Spring Kong FM: Simple factors associated with radiation-induced lung toxicity after stereotactic body radiation therapy of the thorax: a pooled analysis of 88 studies. Int $\mathbf{J}$ Radiat Oncol Biol Phys 95(5): 1357-1366, 2016. PMID: 27325482. DOI: 10.1016/j.ijrobp.2016.03.024

5 Yamaguchi S, Ohguri T, Ide S, Aoki T, Imada H, Yahara K, Narisada $\mathrm{H}$ and Korogi $\mathrm{Y}$ : Stereotactic body radiotherapy for lung tumors in patients with subclinical interstitial lung disease: the potential risk of extensive radiation pneumonitis. Lung Cancer 82(2): 260-265, 2013. PMID: 24054547. DOI: 10.1016/ j.lungcan.2013.08.024

6 Ueki N, Matsuo Y, Togashi Y, Kubo T, Shibuya K, Iizuka Y, Mizowaki T, Togashi K, Mishima M and Hiraoka M: Impact of pretreatment interstitial lung disease on radiation pneumonitis and survival after stereotactic body radiation therapy for lung cancer. J Thorac Oncol 10(1): 116-125, 2015. PMID: 25376512. DOI: $10.1097 /$ JTO.0000000000000359

7 Yoshitake T, Shioyama Y, Asai K, Nakamura K, Sasaki T, Ohga S, Kamitani T, Yamaguchi T, Ohshima K, Matsumoto K, Kawanami $\mathrm{S}$ and Honda $\mathrm{H}$ : Impact of interstitial changes on radiation pneumonitis after stereotactic body radiation therapy for lung cancer. Anticancer Res 35(9): 4909-4913, 2015. PMID: 26254387.

8 Onishi H, Yamashita H, Shioyama Y, Matsumoto Y, Takayama K, Matsuo Y, Miyakawa A, Matsushita H, Aoki M, Nihei K, Kimura T, Ishiyama H, Murakami N, Nakata K, Takeda A, Uno T, Nomiya T, Takanaka T, Seo Y, Komiyama T, Marino K, Aoki S, Saito R, Araya M, Maehata Y, Tominaga L and Kuriyama K: Stereotactic body radiation therapy for patients with pulmonary interstitial 
change: High incidence of fatal radiation pneumonitis in a retrospective multi-institutional study. Cancers (Basel) 10(8): 257, 2018. PMID: 30072613. DOI: 10.3390/cancers 10080257

9 Georg D, Hillbrand M, Stock M, Dieckmann K and Pötter R: Can protons improve SBRT for lung lesions? Dosimetric considerations. Radiother Oncol 88(3): 368-375, 2008. PMID: 18405986. DOI: $10.1016 /$ j.radonc. 2008.03 .007

10 Macdonald OK, Kruse JJ, Miller JM, Garces YI, Brown PD, Miller RC and Foote RL: Proton beam radiotherapy versus threedimensional conformal stereotactic body radiotherapy in primary peripheral, early-stage non-small-cell lung carcinoma: a comparative dosimetric analysis. Int J Radiat Oncol Biol Phys 75(3): 950-958, 2009. PMID: 19801106. DOI: 10.1016/j.jrobp.2009.04.023

11 Hoppe BS, Huh S, Flampouri S, Nichols RC, Oliver KR, Morris CG, Mendenhall NP and Li Z: Double-scattered proton-based stereotactic body radiotherapy for stage I lung cancer: a dosimetric comparison with photon-based stereotactic body radiotherapy. Radiother Oncol 97(3): 425-430, 2010. PMID: 20934768. DOI: 10.1016/j.radonc.2010.09.006

12 Kadoya N, Obata Y, Kato T, Kagiya M, Nakamura T, Tomoda T, Takada A, Takayama K and Fuwa N: Dose-volume comparison of proton radiotherapy and stereotactic body radiotherapy for nonsmall-cell lung cancer. Int J Radiat Oncol Biol Phys 79(4): 12251231, 2011. PMID: 20732759. DOI: 10.1016/j.jijobp.2010.05.016

13 Wink KCJ, Roelofs E, Simone CB 2nd, Dechambre D, Santiago A, van der Stoep J, Dries W, Smits J, Avery S, Ammazzalorso F, Jansen N, Jelen U, Solberg T, de Ruysscher D and Troost EGC: Photons, protons or carbon ions for stage I non-small cell lung cancer - Results of the multicentric ROCOCO in silico study. Radiother Oncol 128(1): 139-146, 2018. PMID: 29545019. DOI: $10.1016 /$ j.radonc.2018.02.024

14 Ono T, Hareyama M, Nakamura T, Kimura K, Hayashi Y, Azami Y, Hirose K, Hatayama Y, Suzuki M, Wada H, Kikuchi Y and Nemoto K: The clinical results of proton beam therapy in patients with idiopathic pulmonary fibrosis: a single center experience. Radiat Oncol 11: 56, 2016. PMID: 27090216. DOI: 10.1186/s13014-016-0637-3

15 Sobin LH, Gospodarowicz MK and Wittekind C: TNM Classification of Malignant Tumours, Seventh Edition. New Jersey, Wiley-Blackwell, pp. 138-146, 2009.

16 Raghu G, Remy-Jardin M, Myers JL, Richeldi L, Ryerson CJ, Lederer DJ, Behr J, Cottin V, Danoff SK, Morell F, Flaherty KR, Wells A, Martinez FJ, Azuma A, Bice TJ, Bouros D, Brown KK, Collard HR, Duggal A, Galvin L, Inoue Y, Jenkins RG, Johkoh T, Kazerooni EA, Kitaichi M, Knight SL, Mansour G, Nicholson AG, Pipavath SNJ, Buendía-Roldán I, Selman M, Travis WD, Walsh S, Wilson KC and American Thoracic Society, European Respiratory Society, Japanese Respiratory Society, and Latin American Thoracic Society: Diagnosis of Idiopathic Pulmonary Fibrosis. An Official ATS/ERS/JRS/ALAT Clinical Practice Guideline. Am J Respir Crit Care Med 198(5): e44-e68, 2018. PMID: 30168753. DOI: 10.1164/rccm.201807-1255ST

17 Kazerooni EA, Martinez FJ, Flint A, Jamadar DA, Gross BH, Spizarny DL, Cascade PN, Whyte RI, Lynch JP 3rd and Toews G: Thin-section CT obtained at $10-\mathrm{mm}$ increments versus limited three-level thin-section CT for idiopathic pulmonary fibrosis: correlation with pathologic scoring. AJR Am J Roentgenol 169(4): 977-983, 1997. PMID: 9308447. DOI: 10.2214/ajr.169.4.9308447

18 Bahig H, Filion E, Vu T, Chalaoui J, Lambert L, Roberge D, Gagnon M, Fortin B, Béliveau-Nadeau D, Mathieu D and
Campeau MP: Severe radiation pneumonitis after lung stereotactic ablative radiation therapy in patients with interstitial lung disease. Pract Radiat Oncol 6(5): 367-374, 2016. PMID: 27068780. DOI: $10.1016 /$ j.prro.2016.01.009

19 Glick D, Lyen S, Kandel S, Shapera S, Le LW, Lindsay P, Wong O, Bezjak A, Brade A, Cho BCJ, Hope A, Sun A and Giuliani M: Impact of pretreatment interstitial lung disease on radiation pneumonitis and survival in patients treated with lung stereotactic body radiation therapy (SBRT). Clin Lung Cancer 19(2): e219e226, 2018. PMID: 29066051. DOI: 10.1016/j.cllc.2017.06.021

20 Liu Y, Zhu Y, Wu R, Hu M, Zhang L, Lin Q, Weng D, Sun X, Liu Y and $\mathrm{Xu} Y$ : Stereotactic body radiotherapy for early stage non-small cell lung cancer in patients with subclinical interstitial lung disease. Transl Lung Cancer Res 9(6): 2328-2336, 2020. PMID: 33489796. DOI: 10.21037/tlcr-20-1050

21 Nakajima M, Yamamoto N, Hayashi K, Karube M, Ebner DK, Takahashi W, Anzai M, Tsushima K, Tada Y, Tatsumi K, Miyamoto T, Tsuji H, Fujisawa T and Kamada T: Carbon-ion radiotherapy for non-small cell lung cancer with interstitial lung disease: a retrospective analysis. Radiat Oncol 12(1): 144, 2017. PMID: 28865463. DOI: 10.1186/s13014-017-0881-1

22 Okano N, Kubo N, Yamaguchi K, Kouno S, Miyasaka Y, Mizukami T, Shirai K, Saitoh JI, Ebara T, Kawamura H, Maeno $\mathrm{T}$ and Ohno T: Efficacy and safety of carbon-ion radiotherapy for stage I non-small cell lung cancer with coexisting interstitial lung disease. Cancers (Basel) 13(16): 4204, 2021. PMID: 34439358. DOI: $10.3390 /$ cancers 13164204

23 Barriger RB, Forquer JA, Brabham JG, Andolino DL, Shapiro RH, Henderson MA, Johnstone PA and Fakiris AJ: A dosevolume analysis of radiation pneumonitis in non-small cell lung cancer patients treated with stereotactic body radiation therapy. Int J Radiat Oncol Biol Phys 82(1): 457-462, 2012. PMID: 21035956. DOI: 10.1016/j.ijrobp.2010.08.056

24 Yamashita H, Kobayashi-Shibata S, Terahara A, Okuma K, Haga A, Wakui R, Ohtomo K and Nakagawa K: Prescreening based on the presence of CT-scan abnormalities and biomarkers (KL6 and SP-D) may reduce severe radiation pneumonitis after stereotactic radiotherapy. Radiat Oncol 5: 32, 2010. PMID: 20459699. DOI: $10.1186 / 1748-717 X-5-32$

25 Chaudhuri AA, Binkley MS, Rigdon J, Carter JN, Aggarwal S, Dudley SA, Qian Y, Kumar KA, Hara WY, Gensheimer M, Nair VS, Maxim PG, Shultz DB, Bush K, Trakul N, Le QT, Diehn M, Loo BW Jr and Guo HH: Pre-treatment non-target lung FDG-PET uptake predicts symptomatic radiation pneumonitis following Stereotactic Ablative Radiotherapy (SABR). Radiother Oncol 119(3): 454-460, 2016. PMID: 27267049. DOI: 10.1016/ j.radonc.2016.05.007

26 Tsujino K, Hashimoto T, Shimada T, Yoden E, Fujii O, Ota Y, Satouchi M, Negoro S, Adachi S and Soejima T: Combined analysis of V20, VS5, pulmonary fibrosis score on baseline computed tomography, and patient age improves prediction of severe radiation pneumonitis after concurrent chemoradiotherapy for locally advanced non-small-cell lung cancer. J Thorac Oncol 9(7): 983-990, 2014. PMID: 24922010. DOI: 10.1097/JTO.00000 00000000187

Received September 18, 2021

Revised October 16, 2021

Accepted October 18, 2021 